\title{
THE DETAILED PRIORITY OF INTERNATIONAL FREIGHT EXPRESSES IN THE OVERLAPPING SECTION OF RFC 7 AND RFC 9 KOLÍN - CHOCEŇ
}

\author{
Přemysl ŠrámeK*, TAtiana Molková \\ University of Pardubice, Jan Perner Transport Faculty, Department of Transport Technology and Control, \\ Studentská 95, 532 10 Pardubice, Czech Republic \\ * corresponding author: premysl.sramek@student.upce.cz
}

\begin{abstract}
The main goal of this article is to research the optimal priority of international freight expresses, especially on European freight corridors. This article shows this problem in the context in the overlapping section of RFC 7 and RFC 9 Kolín - Choceň. There is solved changing priority of freight expresses in detail, whereas other train priorities are the same.
\end{abstract}

KEywords: Capacity, freight expresses, freight corridors, timetable stability.

\section{INTRODUCTION}

One of the aims of European transport policy is to redirect capacity of road freight traffic to other modes of transport, where rail transport is an interesting and environmentally friendly alternative, especially in terms of speed, availability and amount of transported cargo. On the other hand, by customers is required delivery time is guaranteed by carriers, what is unfortunately not always possible, especially due to high utilization of European rail infrastructure. The solution is the construction of new lines, increasing the capacity of existing lines through construction and reconstruction measures or through operational measures. Among the operational measures may be included alternative routing of trains as well as changing priorities of a particular type of train, e.g. train category Fex (freight express) [1].

The aim of this article is to find the optimal priority of international freight expresses to satisfy the customers required delivery times due to optimization of train priority.

\section{MAterials AND Methods}

There are mentioned some information about European freight corridors RFC and the simulation method with using of simulation tool SimuT (average delay increment (ADI) calculation).

\subsection{Rail Freight Corridors (RFC)}

On the basis of the European Parliament and the EU Council no. 913/2010 for competitive freight and no. $1316 / 2013$, which is created the Connecting Europe Facility (CEF), is the gradual establishment of rail freight corridors RFC (Rail Freight Corridors). The main aim of the operation of these corridors is to strengthen the competitiveness of railways synergies between rail systems and harmonization of allocation interstate freight routes by national infrastructure managers [2].
Czech Republic, respectively Czech Railway Infrastructure Administration (CRIA), as the infrastructure manager and allocator of capacity, is a member of RFC 5 (Baltic - Adriatic), RFC 7 (Orient / EastMediterranean), RFC 8 (North Sea - Baltic) and RFC 9 (Czechoslovak corridor). Each corridor is operated on the basis of the Corridor information document (CID); each corridor has a single point of contact (C OSS) and allows carriers to apply international prearranged train paths facilitated freight via C-OSS. The request must be filed by information system RNE PCS and must include the cross-border section. This paper deals with the model study of common section of RFC 7 and RFC 9 Kolín - Choceň.

\subsubsection{RFC 7}

RFC 7 - the Orient corridor runs from Central Europe to Eastern- and Southern-Europe connecting 7 member states - Czech Republic, Austria, Slovak Republic, Hungary, Romania, Bulgaria and Greece. The total length of main lines is approx. $3900 \mathrm{~km}$ and the length of alternative and connecting lines is almost $2500 \mathrm{~km}$ altogether. Most limiting factors of RFC 7 are low capacity, speed limit, limited length of trains, limited axle load, not electrified sections and lack of adequate safety equipment (signalling track circuits with $25 \mathrm{~Hz}$ frequency, ETCS, GSM-R, etc.). The railway infrastructure managers and capacity allocation companies responsible for establishing and running RFC7 are committed to offer reliable, high-quality, competitive transport services in order to increase the market demand, to operate the infrastructure costeffectively on the long run through harmonization of technical and procedural conditions and to facilitate the environmentally sustainable development of the European economy and the achievement of a better quality of life for its people (3). In capacity analysis, published in Implementation plan of RFC 7 3, there are found lines with capacity utilization higher than $90 \%$. The longest sections with this high capacity 
utilization are situated in the Czech Republic, concretely sections Poříčany - Pardubice $(65 \mathrm{~km})$ and Choceň - Česká Třebová (25km).

\subsubsection{FRC 9}

RFC 9 - the Czech-Slovak Rail Freight Corridor (CS CORRIDOR) runs from Prague to Čierna nad Tisou (Slovak-Ukrainian border) connecting 2 member states - Czech Republic and Slovak Republic. The total length of main lines is $972 \mathrm{~km}$ and the length of alternative and connecting lines is $276 \mathrm{~km}$ altogether. Most limiting factors of RFC 9 are the same as in RFC 7. In capacity analysis, published in Implementation plan of RFC9 [4, there are found lines with capacity utilization higher than $90 \%$.

\subsection{The SIMULATION METHOD}

In this part is said something about the simulation method in context of the transit of international freight express trains (Fex) in the overlapping section of RFC 7 and RFC 9 Kolín - Choceň.

In this section there are a total amount of 10 railway stations, in which it is possible overtaking trains (double track line). Interstation sections are divided by an automatic block into track sections; all crossing safety devices are equipped with gates. For simulation was used simulation tool SimuT, developed by Pavel Krýže, PhD. from CRIA.

The simulation tool SimuT is developed in Visual Basic, therefore it can run on every PC with Microsoft Office. It has to be input the option of a simulation, then railway stations and their shortcuts, station tracks for each railway station, line tracks, connection of station and line tracks, length of interstation departments and amount of line departments, type of train for priority, type of train for each number of a train and the path of each train. The simulation program SimuT can put new paths in a daily timetable with the solution for arisen path conflicts [1.

It was used daily timetable 2016, which included the amount of 384 trains. The similar topic was solved in (1), but not so exactly, in the evaluation there were used for Fex only the importance values $0.5 ; 1.7 ; 1.9$ and there was created periodic timetable. In the table 1 are displayed the importance values of trains, which remain the same, and the importance value of Fex is increasing from 0.5 to 2.0 through step 0.1 . Therefore, it was solved 16 simulations, every simulation had 365 simulation runs (whole timetable period).

About train types in Table 1 - EN means EuroNight train, SC is SuperCity train, EC - EuroCity train, IC - InterCity train, $\mathrm{R}$ is fast train, $\mathrm{Sp}$ - speed-up passenger train, Os - stop passenger train. The remaining train types are types of railway cargo transport - Nex is here Fex and its importance value is variable (the research object). $\mathrm{Pn}$ is normal cargo train and $\mathrm{Mn}$ means slow cargo trains servicing e. g. sidings.

Within the simulation program was established the average delay increment (ADI). The average delay

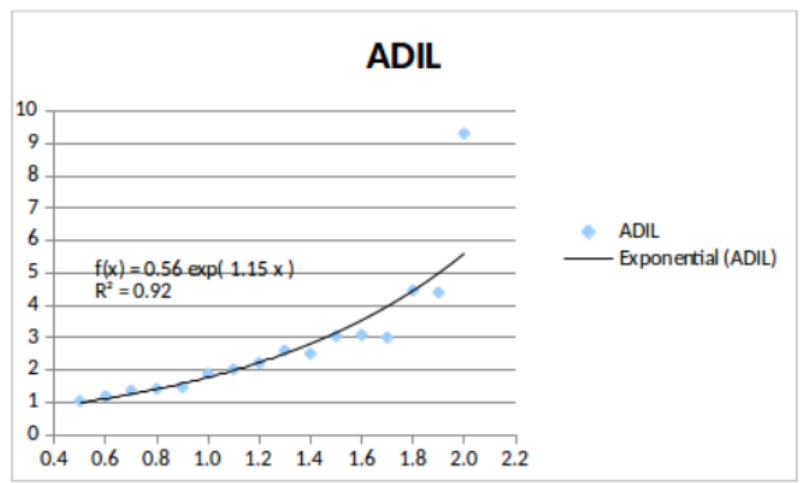

FIgURE 1. ADIL in the relation with Fex importance value.

increment was calculated by dividing the difference between total output and total input delay and the total number of trains. This indicator was calculated as an ongoing basis for each simulation run, so the total for the entire graph (all simulation runs). The indicator was also calculated for different types of transport, i.e. for long-distance passenger transport (ADIL), regional passenger transport (ADIR) and freight transport (ADIF). As part of the simulation was set for all simulation runs random entry delay based on the exponential probability distribution. There were solved conflicts of station tracks, freight trains were allowed to ride before their schedule time (in the case of free capacity) [1].

\section{Results And Discussion}

In the Table 2 there are displayed timetable stability indicators (ADI, ADIL, ADIR, ADIF) in the relation with changing importance value of Fex. All timetable stability indicators have unit min/train, it means every train of the category should get this delay in minutes.

The timetable stability indicators are in the relation with Fex importance value compared on the Figure 1 (ADIL), Figure 2 (ADIR), Figure 3 (ADIF) and Figure 4 (ADI).

ADIL is with increasing Fex importance value just always increasing and it is logical - cargo transport has more and more preference. In the case, when Fex importance value is the same as the Ex importance value, it means 2.0, is ADIL strongly rising to 9.31 min/train. Against Fex important value 1.9 (4.39 min/train) is twofold value - the result is Fex can't have higher or the same priority as Ex. On the Figure 1 there is created the linking curve with the equation and reliability. For ADIL has the highest reliability exponential linking curve.

On the Figure 2 there is displayed ADIR - in this case is evaluation very difficult. The linking curve reliability is the best for polynomial linking curve. Over 1.5 Fex importance value is ADIR affirmative, the best compromise is for Fex importance value 1.3 ADIR is $-0.27 \mathrm{~min} /$ train. The result is Fex should 


\begin{tabular}{|l||c|c|c|c|c|c|c|c|c|c|c|c|c|}
\hline Train type & EN & SC & EC & IC & Ex & R & Sp & Os & Sv & Nex & Pn & Mn & Lv \\
\hline Importance value & 2.5 & 1.8 & 3.0 & 2.8 & 2.0 & 1.8 & 1.5 & 1.0 & 0.3 & var. & 0.1 & 0.03 & 0.08 \\
\hline
\end{tabular}

TABLE 1. The train importance values.

\begin{tabular}{|l|c|c|c|c|}
\hline $\begin{array}{l}\text { Fex impor- } \\
\text { tance value }\end{array}$ & ADIL & ADIR & ADIF & ADI \\
\hline \hline 0.5 & 1.04 & -0.54 & 1.19 & 0.84 \\
\hline 0.6 & 1.19 & -0.61 & 1.63 & 1.07 \\
\hline 0.7 & 1.36 & -0.37 & 1.21 & 1.02 \\
\hline 0.8 & 1.42 & -0.30 & 1.12 & 1.02 \\
\hline 0.9 & 1.47 & -0.51 & 1.31 & 1.09 \\
\hline 1.0 & 1.88 & -0.31 & 0.46 & 0.97 \\
\hline 1.1 & 2.02 & -0.08 & 0.31 & 1.01 \\
\hline 1.2 & 2.22 & -0.12 & 0.39 & 1.12 \\
\hline 1.3 & 2.60 & -0.27 & -0.38 & 0.96 \\
\hline 1.4 & 2.50 & -0.06 & 0.79 & 1.42 \\
\hline 1.5 & 3.05 & 0.05 & 0.25 & 1.47 \\
\hline 1.6 & 3.08 & 0.01 & 0.57 & 1.60 \\
\hline 1.7 & 3.00 & 0.06 & -0.17 & 1.28 \\
\hline 1.8 & 4.46 & 0.31 & -0.36 & 1.89 \\
\hline 1.9 & 4.39 & 0.01 & -0.72 & 1.67 \\
\hline 2.0 & 9.31 & 0.53 & -1.44 & 3.66 \\
\hline
\end{tabular}

TABLE 2. Timetable stability indicators in the relation of changing Fex importance value.

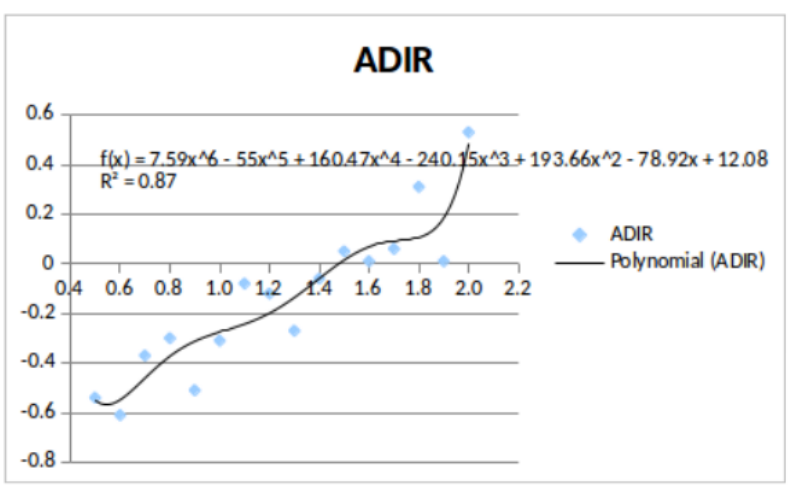

Figure 2. ADIR in the relation with Fex importance value.

have higher priority than regional passenger trains, especially than stop passenger trains.

The linking curve reliability for ADIF is the best for polynomial linking curve. From 1.7 Fex importance value is ADIF always negative and decreasing, but negative is for $1.3 \mathrm{Fex}$ importance value, too. The result is here not so clear.

On the Figure 4 there is displayed average delay increment for whole timetable. In every case is the timetable unstable, ADI is affirmative, the output delay is higher than the input delay. The linking curve has really high reliability for polynomial. For 2.0 Fex importance value is ADI getting really high due to increasing ADIL. Less than $1 \mathrm{~min} /$ train is ADI only in 3 cases - for Fex importance values 0.5, 1.0 and 1.3. The best ADI is for 0.5 (0.84 min/train), but

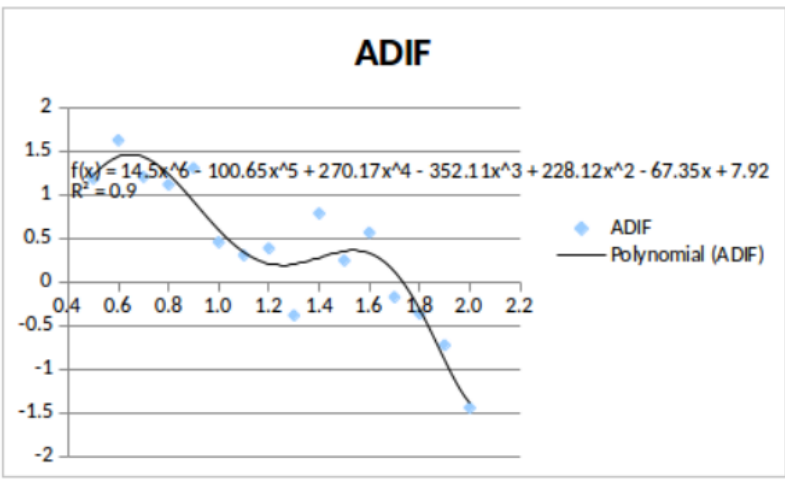

Figure 3. ADIF in the relation with Fex importance value.

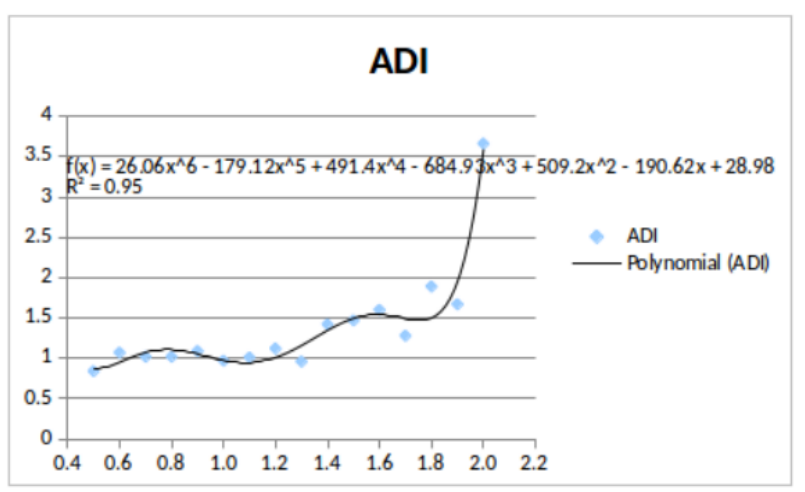

Figure 4. ADI in the relation with Fex importance value.

it is in contrast with higher Fex priority than regional passenger trains priority. The second best ADI is for 1.3 (0.96 min/train), ADIL is $2.60 \mathrm{~min} /$ train, ADIR is $-0.27 \mathrm{~min} /$ train and ADIF is $-0.38 \mathrm{~min} /$ train. According to previous results the total result for best possible timetable stability is to set the Fex importance value for chosen timetable to 1.3. And it corresponds the rules of prescription CRIA D1 [5], where the Fex trains have importance between stop and speed-up passenger trains $(1.0-1.5)$.

\section{Conclusions}

It was checked in detail the relation between the importance of Fex trains and timetable stability. There were made 16 simulation variants in simulation program SimuT and then compared results. The research result is clear - for timetable 2016 in the overlapping section RFC 7 and RFC 9 Kolín - Choceň is necessary for best possible timetable stability to set the Fex importance value (priority) to 1.3 , it means between stop passenger trains priority and speed-up passenger trains priority. It corresponds in the Czech Republic 
the contemporary prescription statement - it suffices only to keep it.

\section{ACKNOWLEDGEMENTS}

This paper is supported by SGS.

\section{REFERENCES}

[1] P.Šrámek, T.Molková. The priority of international freight expresses in the overlapping section of RFC 7 and RFC 9 Kolín - Česká Třebová. Studentská vědecká konference Interoperabilita v železniční dopravě IRICON 2016 - sborník, 2016. ISBN 978-80-01-05939-5.
[2] R.Čech, M.Šlachtová. Železniční nákladní koridory RFC. Železniční magazín Czech Raildays, M-PRESSE plus, s. r. o., 2015. ISSN 1212-1851.

[3] RFC 7 Orient Corridor, Implementation plan of rail freight corridor 7 Orient Corridor [online], 2015. [cit. 2015-20-11].

[4] RFC 9 CS Corridor, Implementation plan of rail freight corridor 9 [online], 2013. [cit. 2015-23-11].

[5] SŽDC. D1 Dopravní a návěstní předpis. SŽDC, s. o., 2013. 